\title{
SCIENTIFIC PROCEEDINGS.
}

\section{Abstracts of the Communications.}

Forty seventh meeting.

The Laboratory of Natural History, College of the City of New York. February 21, I9I2. President Morgan in the chair.

$$
24 \text { (633) }
$$

The fermentation of carbohydrates and other organic media by streptococci.

\section{By C. E. A. W'INSLOW.}

[From the Department of Public Health, American Museum of Natural History, New York.]

The study of the fermentative powers of the streptococci has been carried out in England by merely noting the change of color in litmus media. In this country, Palmer and the writer, Broadhurst and Hilliard have used the more exact methods of titrating inoculated tubes and uninoculated controls, using phenolphthalein as an indicator and plotting the quantitative results obtained. The line of demarcation between fermenting and non-fermenting forms is drawn at the intermodal point between the peaks of the curve. A comparison of several hundred results obtained by English and American methods shows that the English method gives a uniformly higher proportion of fermenters, suggesting that a number of strains producing a very slight amount of acid and properly classed as non-fermenters, are recorded as positive by the English method.

A study of the correlations between action on different organic media shows that those substances tested may be arranged in a definite order of availability, such that a positive reaction in one medium usually implies that all those earlier in the series will be fermented, while failure to act on a given substance almost always implies that substances later in the series will not be fermented either. Among the streptococci dextrose comes first in order of availability, then the disaccharides, lactose and saccharose, and the glucoside, salicin (which easily yields a simple sugar). The 
starch-like body inulin and the alcohol mannit come next and the trisaccharide raffinose is least available of all. This order corresponds to the size of the molecule, whereas in the $B$. coli group, the configuration of the molecule is the main thing, the aldehydic sugars being acted upon very readily, and the ketonic sugars less readily. The bacillus of the colon group which can utilize the ketonic disaccharide can almost always utilize the ketonic trisaccharide raffinose as well.

\section{$25(634)$}

The comparative resistance of spores and vegetative cells of bacteria towards calcium hypochlorite.

By C. M. HILLIARD.

[From the College of the City of New York.]

At least three distinct grades of resistance to the disinfectant action of calcium hypochlorite may be recognized among the bacteria. They are respectively ordinary vegetative cells, acidfast organisms, having a fatty composition, and the true spore cells. The present study is concerned only with the vegetative cell and the spore. Subsequent work will be done with the tubercle bacillus as representing the acid-fast group.

Pure cultures of $B$. coli, B. prodigiosus, B. subtilis (spore former) and $B$. anthracis (spore former) were grown in broth for a time sufficient for spores to appear in large numbers in the two latter cultures. A few drops were then transferred to dilution bottles, the initial number present was determined, and the calcium hypochlorite of known strength was added in carefully weighed amount. Agar plates were made at intervals and the reduction determined.

The results of the work to date may be summarized as follows:

I. The sterilizing action of calcium hypochlorite in water is very rapid at first, the maximum reduction being nearly complete in three hours.

2. Of the organisms studied, B. subtilis is most resistant, followed by $B$. anthracis, and then by the non-spore formers, $B$. coli and $B$. prodigiosus.

3. At least $\mathbf{I} .5$ parts of available chlorin to $\mathbf{I}, 000,000$ parts 